\title{
Thorax
}

\section{Delivering Low-dose CT Screening for Lung Cancer: A Pragmatic Approach}

\begin{tabular}{|r|l|}
\hline Journal: & Thorax \\
\hline Manuscript ID & thoraxjnl-2020-215131.R1 \\
\hline Article Type: & Controversies and challenges in respiratory medicine \\
\hline Date Submitted by the & n/a \\
\hline Complete List of Authors: & $\begin{array}{l}\text { Horst, Carolyn; University College London, Lungs for Living Research } \\
\text { Centre, UCL Respiratory } \\
\text { Dickson, Jennifer; University College London, Lungs for Living Research } \\
\text { Centre, UCL Respiratory } \\
\text { Tisi, Sophie; University College London Lungs for Living Research Centre, } \\
\text {; Basildon University Hospital, } \\
\text { Ruparel, Mamta; University College London, Lungs for Living Research } \\
\text { Centre, UCL Respiratory } \\
\text { Nair, Arjun; University College London Hospitals NHS Foundation Trust } \\
\text { Devaraj, Anand; Royal Brompton Hospital, } \\
\text { Janes, Sam; University College London, Lungs for Living Research } \\
\text { Centre, UCL Respiratory }\end{array}$ \\
\hline Keywords: & \begin{tabular}{l} 
Lung Cancer, Imaging/CT MRI etc, Clinical Epidemiology \\
\hline
\end{tabular} \\
\hline
\end{tabular}

\section{SCHOLARONE ${ }^{m}$ Manuscripts}




\section{TITLE PAGE}

Delivering Low-dose CT Screening for Lung Cancer: A Pragmatic Approach

Carolyn Horst ${ }^{1 \$}$, Jennifer Dickson ${ }^{1 \$}$, Sophie Tisi ${ }^{1}$, Mamta Ruparel ${ }^{1}$, Arjun Nair ${ }^{1 *}$, Anand Devaraj ${ }^{2 *}$, Sam M Janes ${ }^{1 *}$

${ }^{1}$ Lungs for Living Research Centre, UCL Respiratory, University College London, 5 University Street, London, WC1E 6JF, UK.

${ }^{2}$ Royal Brompton and Harefield NHS Foundation Trust, Britten Street, London, SW3 6NJ, UK.

$\$ C$ Horst and J Dickson contributed equally to this work.

* Corresponding Authors:

Arjun Nair, arjun.nair1@nhs.net

Anand Devaraj, a.devaraj@rbht.nhs.uk

Sam M Janes, s.janes@ucl.ac.uk

Keywords:

Lung Cancer, Mass Screening, Computed Tomography, Solitary Pulmonary

Nodule

Word count: 1657 


\begin{abstract}
Low-dose CT screening for lung cancer saves lives by identifying lung cancers at an early stage when the disease can be cured. The challenge that remains for Lung Cancer Screening (LCS) is delivering it in a way that minimises harms and maximises benefits for both patients and health care practitioners. We present here the SUMMIT Study's approach to classification and management of pulmonary nodules and incidental findings identified through LCS, and the way in which this approach to management may enable safe and efficient implementation of LCS in the future.
\end{abstract}




\section{MAIN TEXT}

Lung cancer kills an estimated 35,000 people in the UK every year. Despite the improvements in treating late stage disease, lung cancer outcomes have changed little in the last 40 years. Low-dose CT (LDCT) screening for lung cancer reduces lung cancer mortality by $20-24 \%$, and all-cause mortality by $7 \%(1,2)$. Lung cancer screening (LCS) however remains contentious, particularly how to implement it in an efficient and efficacious way. This contention extends to the potential costs of screening-financial to the NHS, and physical and psychological harms to patients. These concerns are particularly relevant to how we manage both the findings we aim to detect through screening (pulmonary nodules) and those we pick up inadvertently (incidental findings). The SUMMIT Study is the largest CT screening study in Europe and a key endpoint is detailing the feasibility of delivering CT screening across a complete population within the NHS. We present here SUMMIT's approach to nodule and incidental findings management; a pragmatic model that is neither overly burdensome, nor unsafe, and provides a practical solution to some of the challenges of LDCT LCS.

\section{The SUMMIT Study}

The SUMMIT Study (clinicaltrials.gov NCT03934866) is a lung cancer screening study, recruiting 55-77 year olds at high risk of lung and other smoking-related cancers to LDCT screening. Its twin aims are to examine the performance of delivering an LDCT screening service for lung cancer to a high-risk population, and to validate a cell-free nucleic acid blood test for detection of multiple cancers. The study began enrolment in April 2019 after the development of protocols for the management of pulmonary nodules and incidental findings that enabled a consistent approach to management across the entirety of the study (target recruitment of 25,000 ). The study aims to deliver a programme of LCS that is pragmatic, evidence-based, and practically deliverable by primary and secondary care, importantly avoiding overzealous investigation of all findings (and therefore potentially increasing harms). Examination of the evidence that medical intervention of incidental findings makes a difference to participants turns out to be sparse, making detailed radiological reporting probably unnecessary. The reader will see here that we provide only limited and highly specific information beyond the presence of lung cancer or pulmonary nodules. It is our hope that this balanced approach will be borne out in the data we collect, bolstering a safe, effective and efficient implementation of LCS. Studies on whether a future health service could manage a more holistic approach, aligning the reporting of incidental findings such as coronary artery calcification, early emphysema and other findings to a more personalised health intervention with intensive smoking advice, cardio-vascular disease prevention and the like, are urgently needed.

\section{Pulmonary Nodules: The Evidence Base}

We utilise the existing evidence-based British Thoracic Society (BTS) guidelines on the management of pulmonary nodules, with some specific alterations. The BTS 
guidelines use nodule size and type, along with other criteria such as a nodule malignancy risk score (Brock score) and volume doubling time (VDT), to calculate appropriate follow-up management on a per-nodule basis. The SUMMIT algorithm follows this method closely, but was adapted in several key ways, including: accommodation for a three-year annual screening programme rather than a oneoff CT chest; changes in the use of the Brock malignancy score; dispensing with VDT calculations in favour of a growth threshold of $\geq 25 \%$ to inform management at three months; a minimum size requirement $\left(200 \mathrm{~mm}^{3}\right)$ before referral to MDT; and 12 month (versus three month) follow up of pure ground glass lesions $\geq 5 \mathrm{~mm}$. The complete SUMMIT Pulmonary Nodule Protocol is available as supplementary material (Figure S1). Deviations were made from BTS guidelines either to minimise the burden on secondary care colleagues (e.g. where MDT referral is not made until a growing nodule is $\geq 200 \mathrm{~mm}^{3}$ ) or where new evidence suggests a safe but more conservative approach (for example, with GGNs, which often resolve or, if persistent, are unlikely to require immediate intervention). The result, we hope, is a blueprint for managing pulmonary nodules in a safe but measured way, minimising unnecessary stress on patients and providers, while intervening appropriately in those nodules most likely to cause harm.

\section{The Challenge of Incidental Findings}

There is considerably less evidence for the appropriate management of incidentally detected non-nodule findings at LCS LDCT, and opinion is split about whether or not to follow up all findings, some, or none (see supplementary material for a detailed description of our approach, Table S1). The NELSON trial have publicly stated that following up even potentially clinically relevant radiological incidental findings does not provide any benefit (3). Other LCS professionals advocate that far more findings are reported back and/or investigated further (4). Given the heterogeneity of evidence, and our wish to create a low interventional burden approach to screening, the SUMMIT protocol reports back incidental findings only where there is an evidence-based clinical action that can be taken to mitigate or further investigate and treat that finding, leading to patient benefit.

The importance of taking a pragmatic approach is highlighted by the fact that incidental findings may be seen in nearly $100 \%$ of participants undergoing lung screening, according to some reports. Identifying and potentially investigating such a high frequency of incidental findings clearly has the potential to constrain lung screening implementation.

Based on the study team's experience delivering the Lung Screen Uptake Trial (LSUT), we had a good understanding of the impact on primary and secondary care primary care colleagues and participants alike when all radiological findings are reported back. The most common incidental findings at LCS are coronary artery calcification (CAC) and emphysema, whose detection and management in the LCS population have been widely discussed but variably applied. CAC is often detected at LDCT and the screening target demographic is at increased risk of cardiovascular disease (CVD) due to their smoking histories and ages; because of 
this, American LCS screening programmes are encouraged to report back CAC to screenees in order to instigate primary prevention, where appropriate (4). In the UK, however, instigation of appropriate management of CVD is based on the calculation of a QRISK2 score. From LSUT data, the vast majority (projected figure $>90 \%$ ) of the SUMMIT population are expected to have a QRISK2 score greater than $10 \%$, the threshold for instigation of primary prevention (5). After consultation with cardiology and general practice colleagues, the study team elected to include a prompt in all letters to participants' GPs recommending assessment via QRISK2 score, an approach which avoids communicating a CAC score, which provides no additional prognostic information nor evidence base for intervention.

Emphysema on CT is another area of contention within the screening and wider lung cancer community. The appearance of emphysema is not currently a criterion for the diagnosis of COPD in the GOLD guidelines, unlike spirometric demonstration of airflow limitation and symptomatology. Reporting back the presence and/or severity of emphysema on LDCT will not lead to a diagnosis of COPD; however, the study does report back to GPs pre-bronchodilator spirometry values and, if the participant does not report a pre-existing diagnosis of COPD but has symptoms and airflow limitation on spirometry (FEV1:FVC $<0.7$ ), a recommendation is provided to the GP to investigate the person formally for COPD. There may be good reasons to report back emphysema, or indeed CAC, to participants as a 'teachable moment' to aid smoking cessation, but evidence is still being gathered to support this assertion. Labelling a participant as having emphysema or CAC may also have psychological downsides as well as adverse consequences for health insurance.

The SUMMIT clinical team is cognizant that undiagnosed non-lung cancers may present on an LDCT performed as part of LCS. Again, the appearances that are sometimes consistent with cancer may also represent benign pathology. Currently there is no evidence that screening for thoracic or upper abdominal cancer (other than lung cancer) with CT is beneficial to screenees. But instead of deciding that there is 'neglectable benefit' (3) in investigating appearances potentially consistent with non-lung cancers, we have implemented what we think is a sensible, often stepped, approach to further investigation and management. For example, adrenal nodules identified at LDCT are assessed for size and density, with those of smaller diameter $(1-4 \mathrm{~cm})$ or Houndsfield Units $(\mathrm{HU})>10$ being rescanned within the study in a year's time to look for stability, and those of larger size instigating immediate referral. This approach is consistent with the American College of Radiology's (ACR) white paper on abdominal incidental findings and, we believe, strikes a balance between intervening in potentially longstanding and stable appearances, and aiding the diagnosis of otherwise unknown cancers. A similarly pragmatic approach was taken to thyroid nodules and other nonmalignant findings (see supplementary material in table S1for more information).

While these protocols may appear complicated, because bespoke reporting proformas and software have been developed for use in SUMMIT, and findings indicated therein are ingested into the software directly, users are automatically presented with the 'correct' management for each scan, and are not required to 
reference these protocols directly themselves. Radiologists may override the management suggested by the software if they feel another management approach is indicated. This means that while the protocols may be detailed, their implementation is user-friendly but flexible where appropriate. Ultimately, the utility of identifying and investigating non-lung-cancer findings in LCS is yet to be determined, and outcome data from SUMMIT may help the wider LCS community understand which findings should be investigated, and those that should be ignored.

SUMMIT has utilised the evidence available in order to develop and implement a consistent approach to findings at LDCT. Compared to breast and cervical cancer screening programmes, LCS is in its relative infancy. We cannot yet be expected to have all the answers on how to deliver it. A pragmatic approach to pulmonary nodules and incidental findings management at LDCT screening will enable us to build a screening programme without causing the collapse of supporting primary and secondary care services, and can be refined in the future, allowing a fledgling service to begin to change lung cancer outcomes now. 


\section{ACKNOWLEDGEMENTS}

The SUMMIT clinical team would like to thank Dr Simon Morley, Professor Margaret Hall-Craggs, and Professor Joanna Porter for their valuable insights during the development of the SUMMIT incidental findings protocol. The authors would also like to thank Dr Tania Anastasiadis and Dr Karen Sennett for their advocacy of lung cancer screening within primary care, and their input on refining the delivery of the SUMMIT Study.

\section{CONTRIBUTORSHIP}

Dr C Horst and Dr J Dickson contributed equally to the writing of this article, and to the development of the guidelines and protocols discussed. All other authors contributed to the development of the materials discussed in the article and to refining the finished manuscript.

\section{FUNDING}

The SUMMIT Study is funded by GRAIL, Inc.

\section{COMPETING INTERESTS}

The SUMMIT Study is funded by GRAIL Inc. S.M.J. is a Wellcome Trust Senior Fellow in Clinical Science and supported by the Rosetrees Trust, UCLH Charitable Foundation and the Roy Castle Lung Cancer Foundation. This work was partially supported by the UCLH/UCL Department of Health's NIHR Biomedical Research Centre's funding scheme, the CRUK Lung Cancer Centre of Excellence and CRUK Early Detection Centre. A.D. declares personal fees from Boehringer Ingelheim Ltd, GlaxoSmithKlein (GSK), Galapagos NV, and Galecto, Inc. C.H., J.D., S.T. and M.R. are funded or part-funded by GRAIL Inc as part of the SUMMIT Study. AN declares that he is a member of the Advisory Board for Aidence BV, The Netherlands, and he is part-funded by the UCLH Biomedical Research Centre (BRC).

\section{EXCLUSIVE LICENCE}

I, the Submitting Author has the right to grant and does grant on behalf of all authors of the Work (as defined in the below author licence), an exclusive licence and/or a non-exclusive licence for contributions from authors who are: i) UK Crown employees; ii) where BMJ has agreed a CC-BY licence shall apply, and/or iii) in accordance with the terms applicable for US Federal Government officers or employees acting as part of their official duties; on a worldwide, perpetual, irrevocable, royalty-free basis to BMJ Publishing Group Ltd ("BMJ") its licensees and where the relevant Journal is co-owned by BMJ to the co-owners of the Journal, to publish the Work in Thorax and any other BMJ products and to exploit all rights, as set out in our licence.

The Submitting Author accepts and understands that any supply made under these terms is made by BMJ to the Submitting Author unless you are acting as an employee on behalf of your employer or a postgraduate student of an affiliated institution which is paying any applicable article publishing charge ("APC") for Open Access articles. Where the Submitting Author wishes to make the Work available on an Open Access basis (and intends to pay the relevant APC), the terms of reuse of such Open Access shall be governed by a Creative Commons 
licence - details of these licences and which Creative Commons licence will apply to this Work are set out in our licence referred to above. 


\section{REFERENCES}

1. Reduced Lung-Cancer Mortality with Low-Dose Computed Tomographic Screening. N Engl J Med [Internet]. 2011 Jun 29;365(5):395-409. Available from: http://dx.doi.org/10.1056/NEJMoa1102873

2. de Koning HJ, van der Aalst CM, de Jong PA, Scholten ET, Nackaerts K, Heuvelmans MA, et al. Reduced Lung-Cancer Mortality with Volume CT Screening in a Randomized Trial. N Engl J Med [Internet]. 2020;1-11. Available from: http://www.ncbi.nlm.nih.gov/pubmed/31995683

3. van de Wiel JCM, Wang Y, Xu DM, van der Zaag-Loonen HJ, van der Jagt EJ, van Klaveren RJ, et al. Neglectable benefit of searching for incidental findings in the Dutch-Belgian lung cancer screening trial (NELSON) using low-dose multidetector CT. Eur Radiol [Internet]. 2007;17(6):1474-82. Available from:

http://ovidsp.ovid.com/ovidweb.cgi?T=JS\&PAGE=reference \&D=med6\&NE $\mathrm{WS}=\mathrm{N} \& \mathrm{AN}=17206426$

4. Mazzone PJ, Silvestri GA, Patel S, Kanne JP, Kinsinger LS, Wiener RS, et al. Screening for Lung Cancer: CHEST Guideline and Expert Panel Report. Chest [Internet]. 2018;153(4):954-85. Available from: https://doi.org/10.1016/j.chest.2018.01.016

5. Ruparel M, Quaife SL, Dickson JL, Horst C, Burke S, Taylor M, et al. Evaluation of cardiovascular risk in a lung cancer screening cohort. Thorax [Internet]. 2019 Sep 26 [cited 2019 Oct 11];74(12):1-7. Available from: http://www.ncbi.nlm.nih.gov/pubmed/31558626 
Supplementary Material

Delivering Low-dose CT Screening for Lung Cancer: A Pragmatic Approach

C Horst ${ }^{1}$, J Dickson ${ }^{1}$, S Tisi ${ }^{1}$, M Ruparel $^{1}$, A Nair ${ }^{*}$, A Devaraj2*, SM Janes ${ }^{1 *}$

${ }^{1}$ Lungs for Living Research Centre, UCL Respiratory, University College London, London, UK.

2Royal Brompton and Harefield NHS Foundation Trust, London, UK.

*Corresponding authors

The SUMMIT Study Pulmonary Nodule and Incidental Finding Management Protocol

The SUMMIT Pulmonary Nodule Protocol

This protocol is based largely on the British Thoracic Society Guideline for the Investigation and Management of Pulmonary Nodules(1). The SUMMIT guidelines have been adapted to a three-year screening programme [baseline (Y0), year 1 (Y1), and year 2 (Y2)] with a randomisation element at the second visit (Y1). Deviations or additions to the BTS guidelines are denoted in bold boxes. Evidence for these changes are cited in call-outs at the bottom of each protocol $(*, \S$ etc) and incorporate best practice recommendations from the Fleischner Society $(2,3)$.

Some general principles when using this protocol:

- Overall management is based on the largest nodule, or the nodule requiring most immediate follow-up.

- At any time point, radiologists can upgrade to next level of management if nodules are felt to have suspicious features and recommended management is felt not to be sufficient.

- Growing solid nodules should be $>200 \mathrm{~mm}^{3}$ (or $8 \mathrm{~mm}$ in diameter if unreliably segmented) before referral to multidisciplinary teams (MDTs) in order to prevent unnecessary referrals to secondary care sites. This is because for smaller nodules, MDTs are likely to recommend surveillance CT anyway, in which case this is best delivered within the screening programme. For nodules that have volumetrically grown $\geq 25 \%$ at 3 months but are $\leq 200 \mathrm{~mm}^{3}$, and nodules with unreliable volumetry that appear to have equivocally grown on visual inspection, a repeat CT in 3 months is performed within the study.

- In cases where volumetry is not possible for a solid nodule and diameter measurements are made, assessment should be based on unequivocal growth (as per BTS Guidelines).

- For sub-solid nodules (SSNs), 'growing morphology' refers to a new or increasing solid component. SSNs with 'altered morphology' refers to bubblelike lucencies or pleural retraction. If the solid component grows but is still $<8 \mathrm{~mm}$, then the increase should be at least $2 \mathrm{~mm}$ since the previous LDCT or observed on two CTs before MDT referral.

- Nodular consolidation $>8 \mathrm{~mm}$ or endobronchial lesions or other nodules $>8 \mathrm{~mm}$ that appear more likely to be inflammatory, but where malignancy is a consideration, may be scanned again at three months. If unchanged or growing at the follow-up scan, these should be referred to MDT. Opacities that are clearly 
inflammatory (eg tree-in-bud or endobronchial mucous) and where malignancy is not a consideration do not require follow up.

- If a part solid nodule has a solid component that is $>90 \%$ of the total nodule size, then this nodule is considered solid and is assessed as such(4).

- Intrapulmonary lymph nodes (IPLNs), also known as perifissural nodules, are nodules with specific benign characteristics, including triangular or lentiform shape, often attached to a fissure. Nodules with these characteristics are highly unlikely to be malignant, and therefore can be marked and tagged with the appropriate classifier, but do not affect management and do not confer any follow-up requirement(5). This approach is consistent with BTS guidelines.

Figure S1—SUMMIT Pulmonary Nodule Protocol Flow Diagrams 


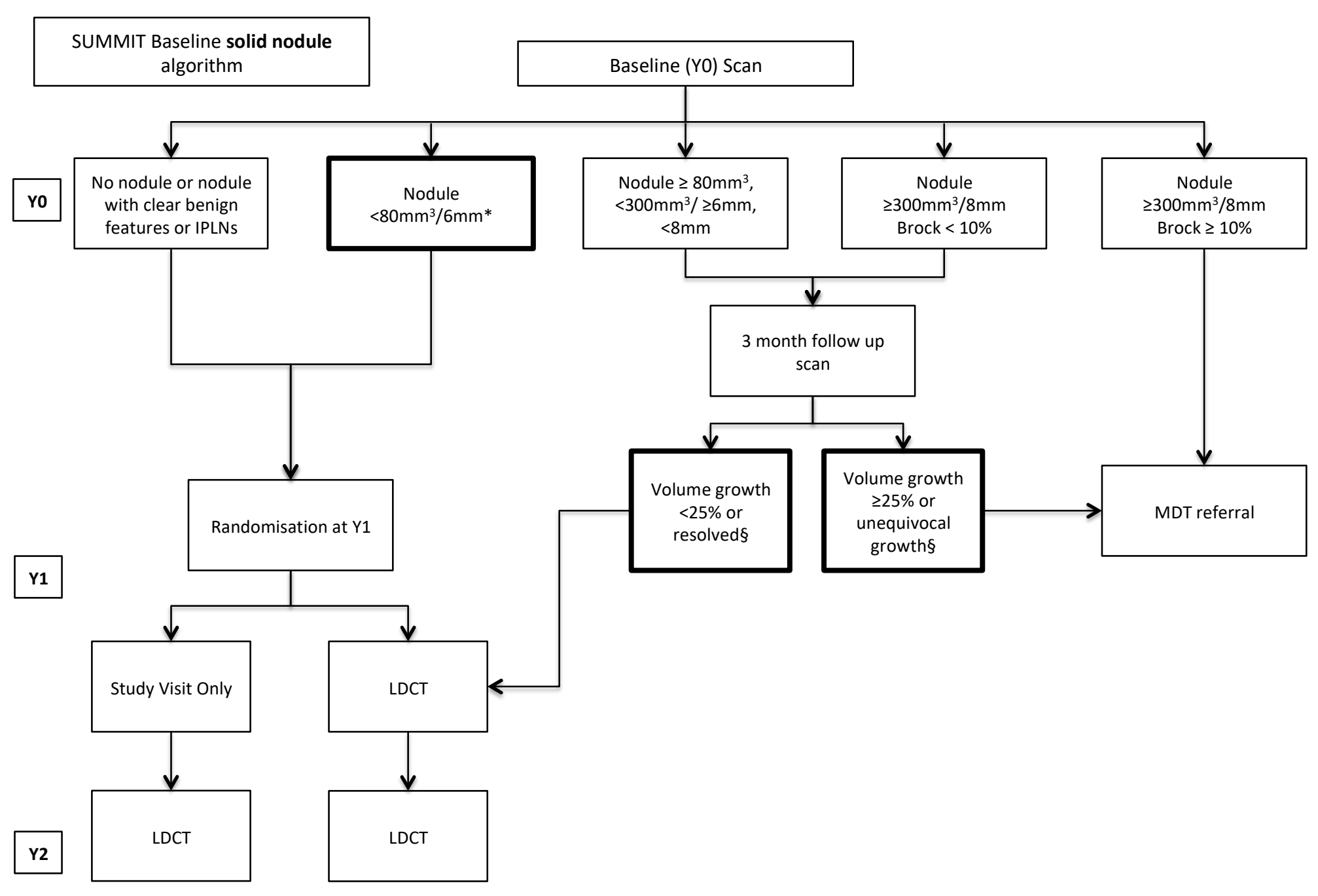




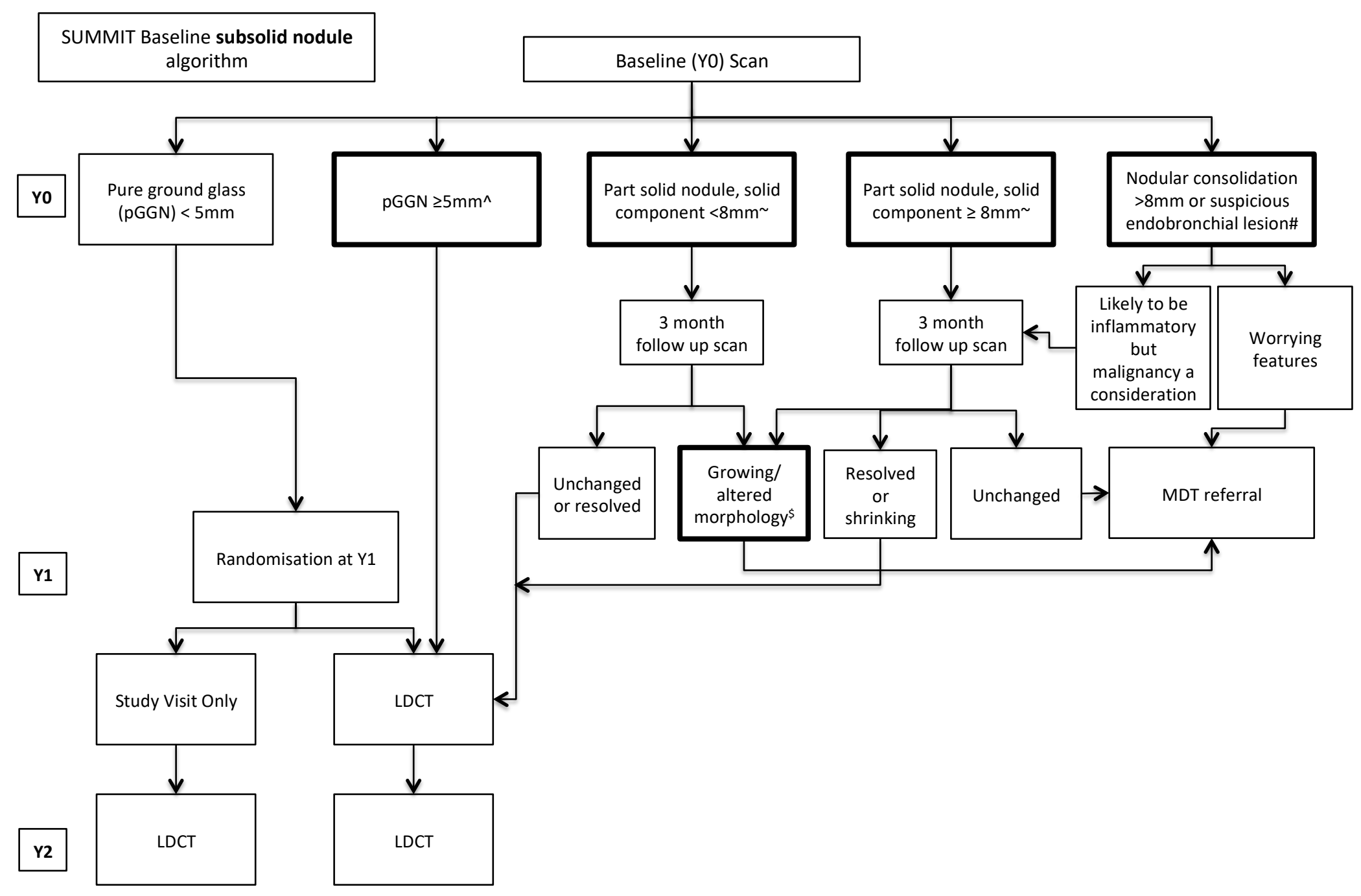




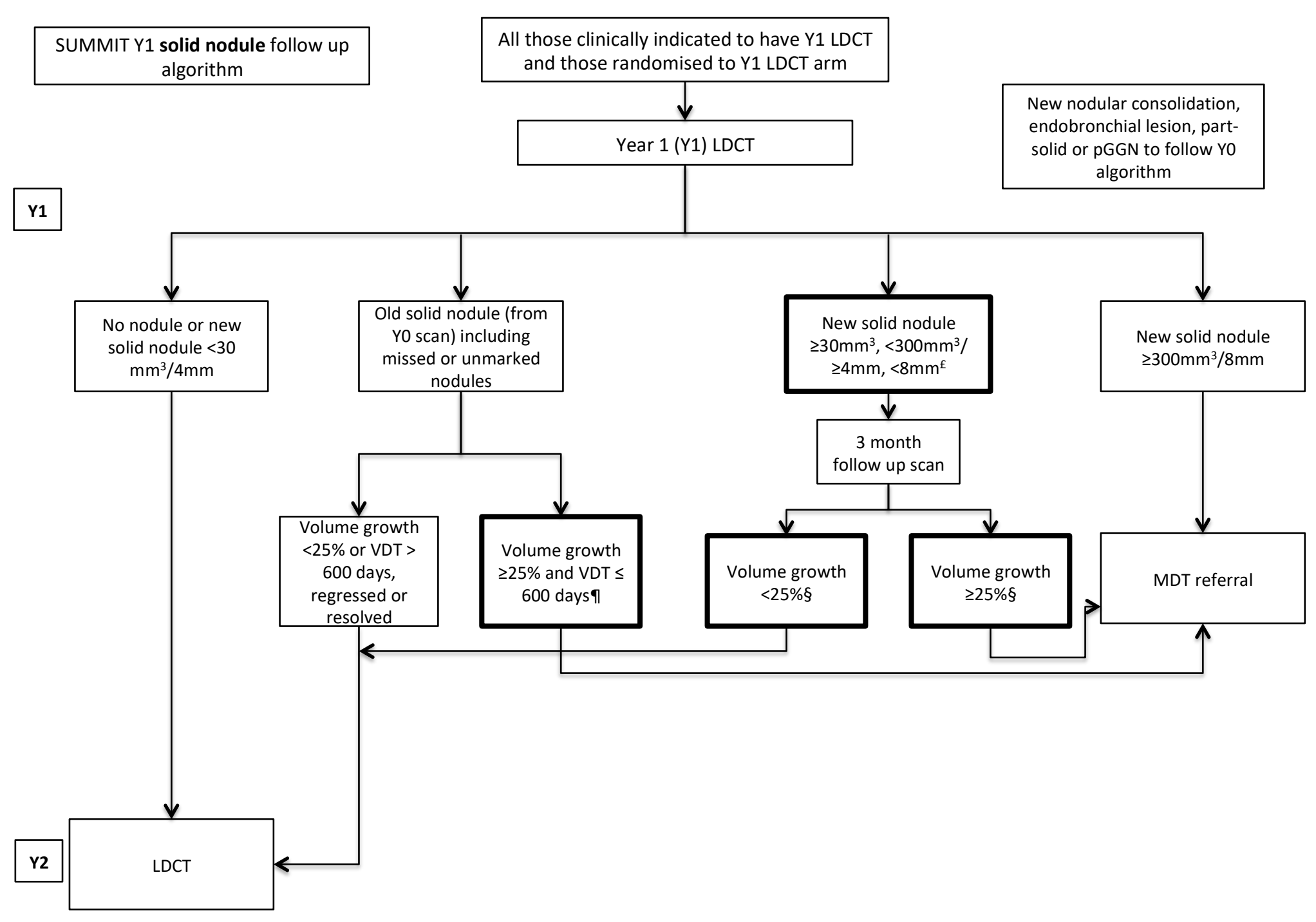




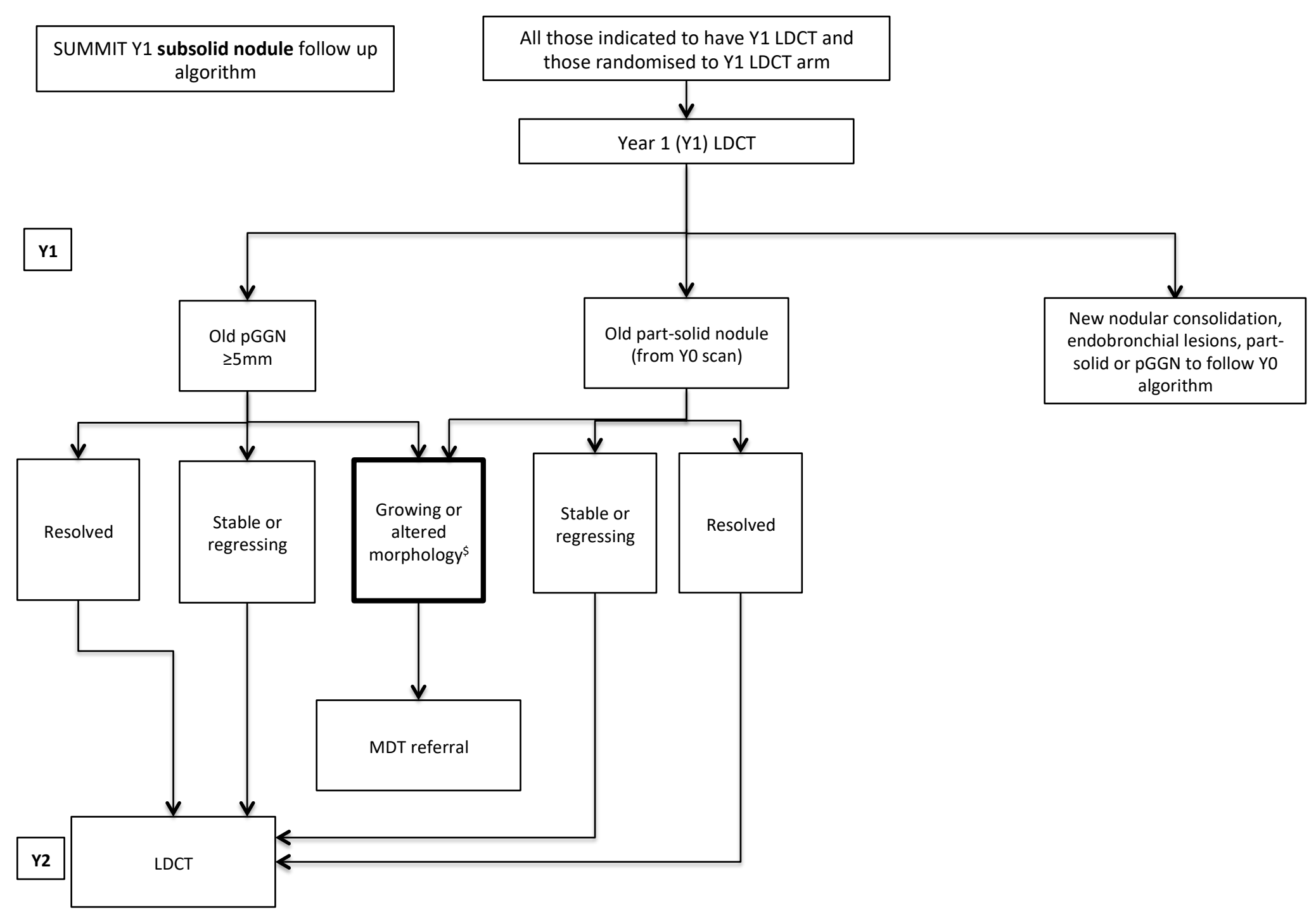




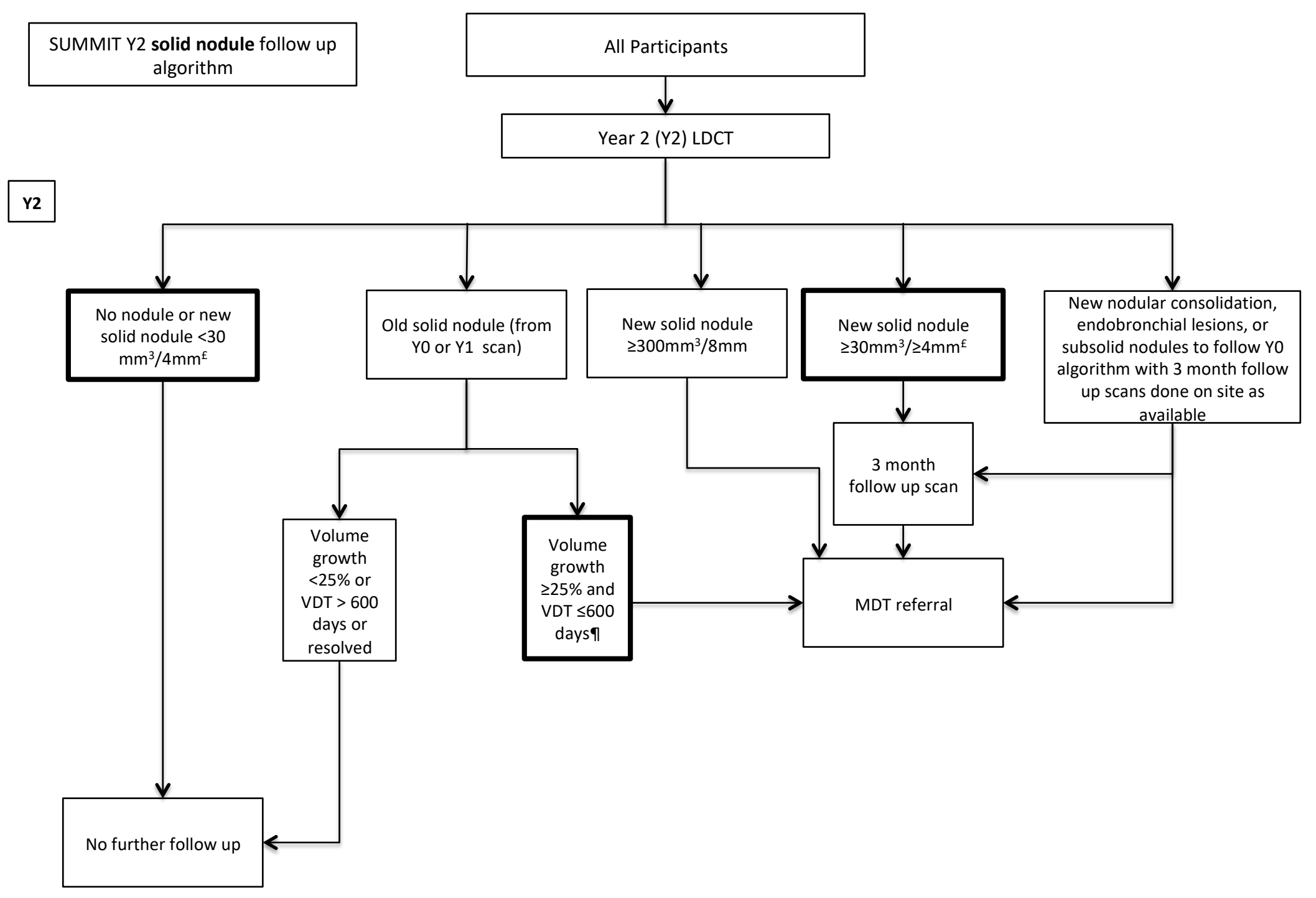




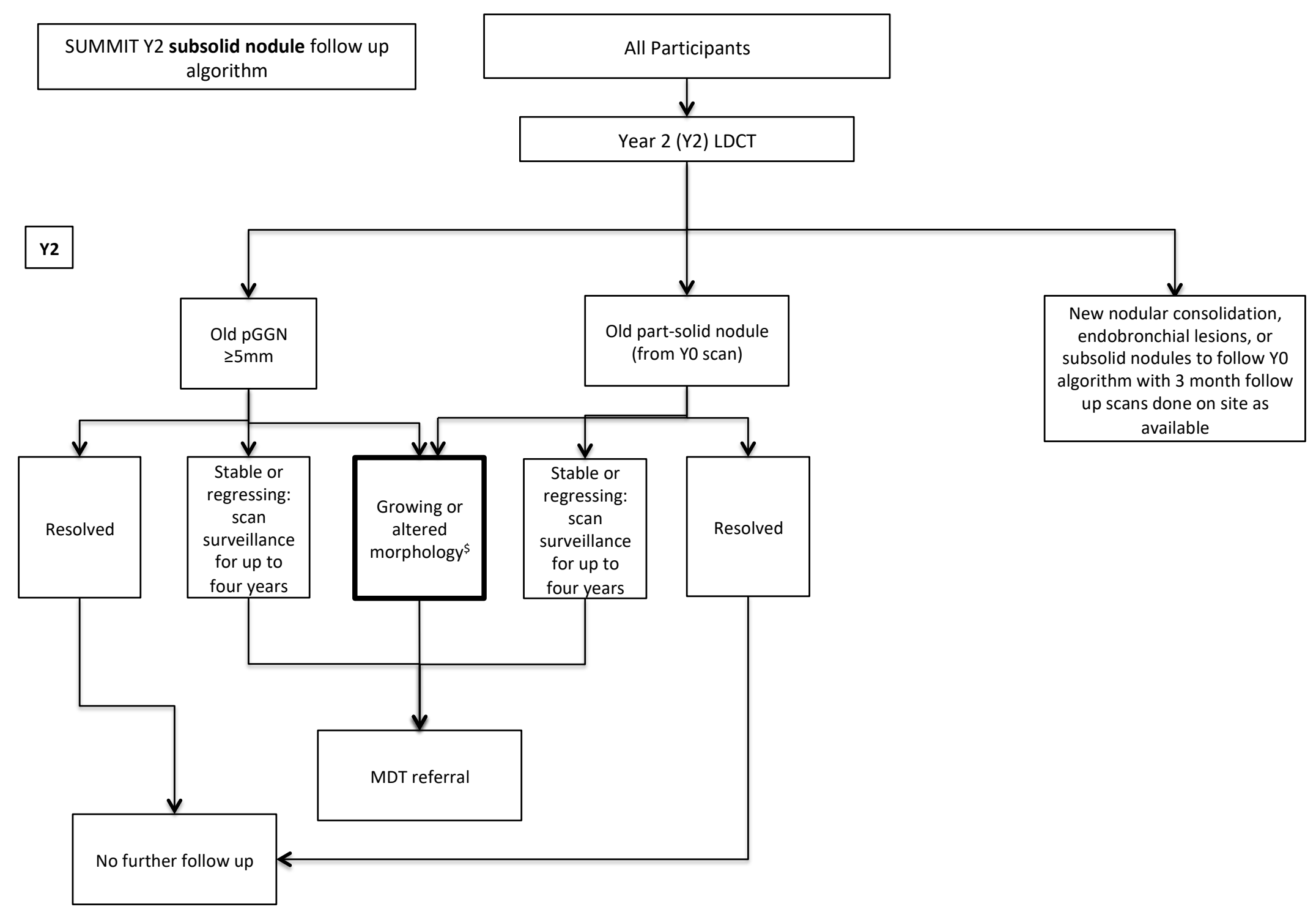




\section{$\underline{\text { KEY }}$}

* Deviation from BTS: no provision for nodules 5-6mm in diameter (where volume not measured) to have 12 month follow up. These will be randomised at $\mathrm{Y} 1$ to annual or biennial scans.

$\S$ Simplification of BTS: Volume doubling time (VDT) is not used for growth assessments at 3 month follow up for new or baseline nodules, as $\geq 25 \%$ growth at 3 months implies a VDT of less than 400 days. If volume growth is $\geq 25 \%$ but the nodule still has a volume $\leq 200 \mathrm{~mm}^{3}$, a repeat scan within the study is indicated, as an MDT referral for a nodule of that size is likely only to instigate further surveillance, which can take place within the study.

${ }^{\wedge}$ Deviation from BTS: GGNs $\geq 5 \mathrm{~mm}$ in diameter will be scanned at Y1 and Y2 for monitoring, but not before. Data has shown that GGNs, if persistent, are likely to represent adenocarcinoma in situ (AIS) are are therefore unlikely to require immediate intervention $(4,6)$.

$\sim$ Deviation from BTS: The Brock Score is not used for assessing PSNs, due to its likelihood of underestimating malignancy in this nodule type. Instead, a distinction has been made regarding the solid component diameter $(<8 \mathrm{~mm} \geq)$ to try to minimise unnecessary referrals to MDTs, for nodules with small solid components that are stable, and may represent indolent or overdiagnosed cancers. For PSNs with larger solid components that persist, referral to MDT is indicated.

\# Addition to BTS: Opacities that are clearly inflammatory (eg tree-in-bud or endobronchial mucous) and where malignancy is not a consideration do not require follow up. Nodular consolidation $>8 \mathrm{~mm}$ or endobronchial lesions or other nodules $>8 \mathrm{~mm}$ that appear more likely to be inflammatory, but where malignancy is a consideration, may be scanned again at three months. If these nodules remain unchanged or are growing at the follow-up scan, they should be referred to MDT. Such opacities if $<8 \mathrm{~mm}$ should follow the normal nodule algorithm.

\$ Addition to BTS: 'Growing morphology' refers to a new or increasing solid component. SSNs with 'altered morphology' refers to bubble-like lucencies or pleural retraction. If the solid component grows but is still $<8 \mathrm{~mm}$, then the increase should be at least $2 \mathrm{~mm}$ since the previous LDCT or observed on two CTs before MDT referral, as a repeat surveillance scan is the most likely outcome from from MDT for a nodule of this size, and this can be performed within the study.

$£$ Addition to BTS for a screening programme: new nodules which have developed since the previous annual scan should have a lower threshold $\left(\geq 30 \mathrm{~mm}^{3}\right.$ or $4 \mathrm{~mm}$ diameter) for follow up, due to increased likelihood of malignancy (7). 
Tा Deviation from BTS: VDT is applied at annual follow up scans and compared to baseline (or Y1) scans, as per BTS. VDT $\leq 600$ days and volume growth of $\geq 25 \%$ is required for MDT referral to be made.; BTS has two VDT cut-offs (400 days and 600 days), which we have amalgamated into one cutoff for simplicity. 


\section{The SUMMIT Study Incidental Findings Management Protocol}

The SUMMIT Study Incidental Findings Management Protocol was developed using guidelines and evidence available at the time of protocol development (2018). Where evidence or guidelines were not available, expert opinion was sought. The table below captures the clinically actionable findings that we are either following up within the study, or are asking that primary or secondary care colleagues follow up, where appropriate. Other data points, not listed here, are being collected for research purposes only, for example coronary artery calcification (CAC) and emphysema, as described in the main article text.

Table S1-SUMMIT Actionable Incidental Findings Protocol

\begin{tabular}{|c|c|c|c|c|}
\hline Condition/finding & Description & Action by & Recommended action & Rationale \\
\hline Lung cancer & $\begin{array}{l}\text { Abnormality suggestive of lung cancer including } \\
\text { consolidation and pleural thickening with worrying } \\
\text { features, or unilateral pleural effusion. }\end{array}$ & Study team & Urgent referral to local lung cancer MDT. & $\begin{array}{l}\text { Routine } \\
\text { standard of } \\
\text { care }\end{array}$ \\
\hline $\begin{array}{l}\text { Other cancer (non- } \\
\text { lung) }\end{array}$ & $\begin{array}{l}\text { Abnormality suggestive of cancer (non-lung) including } \\
\text { breast lesions requiring triple assessment }\end{array}$ & Study team & Urgent referral to local site-specific cancer MDT. & $\begin{array}{l}\text { Routine } \\
\text { standard of } \\
\text { care }\end{array}$ \\
\hline $\begin{array}{l}\text { Emphysema and } \\
\text { COPD }\end{array}$ & $\begin{array}{l}\text { Evidence of airflow limitation on pre-bronchodilator } \\
\text { spirometry (FEV } 1 / \mathrm{FVC}<70 \% \text { ) who are not known to } \\
\text { have COPD and report persistent chronic cough } \\
\text { (duration }>6 \text { weeks) and/or breathlessness (MRC } \\
\text { score }>1 \text { ) }\end{array}$ & GP & $\begin{array}{l}\text { Clinical review and consider post bronchodilator } \\
\text { spirometry assessment for COPD. }\end{array}$ & $\begin{array}{l}\text { NICE } \\
\text { guidelines (8) }\end{array}$ \\
\hline Bronchiectasis & $\begin{array}{l}\text { Severe = luminal diameter relative to the } \\
\text { accompanying artery diameter is greater than three } \\
\text { times the size. }\end{array}$ & GP & $\begin{array}{l}\text { Clinical review and if symptomatic a non-urgent } \\
\text { referral to the local respiratory team. }\end{array}$ & $\begin{array}{l}\text { Relationship } \\
\text { between } \\
\text { bronchiectasis } \\
\text { imaging and } \\
\text { disease } \\
\text { severity(9) }\end{array}$ \\
\hline Interstitial lung & $>10 \%$ reticulation with fibrotic features i.e. traction & GP & Clinical review and non-urgent referral to local & ILD studies \\
\hline
\end{tabular}




\begin{tabular}{|c|c|c|c|c|}
\hline disease & $\begin{array}{l}\text { bronchiectasis, as this denotes significant degree of ILD } \\
\text { that may be clinically significant. }(10,11)\end{array}$ & & respiratory team. & $\begin{array}{l}(10,11) \\
\text { Specialist } \\
\text { opinion }\end{array}$ \\
\hline $\begin{array}{l}\text { Diffuse Pleural } \\
\text { Thickening }\end{array}$ & $\begin{array}{l}\text { Diffuse pleural thickening without overtly worrying } \\
\text { features. }\end{array}$ & Study team & Annual scan within the study. & $\begin{array}{l}\text { Specialist } \\
\text { opinion }\end{array}$ \\
\hline $\begin{array}{l}\text { Bilateral pleural } \\
\text { effusions }\end{array}$ & Bilateral pleural effusions. & GP & $\begin{array}{l}\text { Participant and GP informed of finding and a } \\
\text { recommendation made to investigate further for } \\
\text { transudative causes, as per British Medical Journal } \\
(\mathrm{BMJ}) \text { article. }\end{array}$ & $\mathrm{BMJ}(12)$ \\
\hline $\begin{array}{l}\text { Lower respiratory } \\
\text { tract infection } \\
\text { (LRTI) }\end{array}$ & $\begin{array}{l}\text { Self-reported acute (or deterioration in chronic) cough } \\
<3 \text { weeks duration plus one or more of; fever, pleuritic } \\
\text { pain, increased sputum production, shortness of breath } \\
\text { or wheeze OR currently taking antibiotics prescribed } \\
\text { for LRTI. }\end{array}$ & Study team & $\begin{array}{l}\text { Delay study enrolment and LDCT by } 6 \text { weeks on one } \\
\text { occasion only. Advise individual to seek review by } \\
\text { usual pathway e.g. GP where required for antibiotic } \\
\text { treatment if concerned. }\end{array}$ & $\begin{array}{l}\text { SIGN } \\
\text { guidelines } \\
(13)\end{array}$ \\
\hline \multirow{2}{*}{$\begin{array}{l}\text { Anterior } \\
\text { mediastinal mass } \\
\text { (suspected } \\
\text { thymoma) }\end{array}$} & $<3 \mathrm{~cm}$ maximum diameter & Study team & $\begin{array}{l}\text { Annual scan within study. Inform participant and } \\
\text { GP. If stable on successive scans no further action. }\end{array}$ & \multirow[t]{2}{*}{$\begin{array}{l}\text { ACR White } \\
\text { Paper(14) }\end{array}$} \\
\hline & $\begin{array}{l}\geq 3 \mathrm{~cm} \text { maximum diameter at baseline, } \mathrm{OR}<3 \mathrm{~cm} \text { but } \\
\text { growing on successive scans OR with suspicious } \\
\text { features (invasion, irregularity) OR changing } \\
\text { morphology. }\end{array}$ & Study team & Urgent referral to local lung cancer MDT. & \\
\hline \multirow{3}{*}{$\begin{array}{l}\text { Ascending thoracic } \\
\text { aortic dilatation }\end{array}$} & $<4 \mathrm{~cm}$ & $\mathrm{~N} / \mathrm{A}$ & No further action required. & \multirow{3}{*}{$\begin{array}{l}\text { ACR } \\
\text { Paper(15) }\end{array}$} \\
\hline & $\geq 4 \mathrm{~cm}<5.5 \mathrm{~cm}$ & GP & Non-urgent referral to cardiology team. & \\
\hline & $\geq 5.5 \mathrm{~cm}$ & Study team & Urgent referral to local cardiothoracic team. & \\
\hline Thyroid nodules & $\begin{array}{l}\text { Punctate calcification or associated with local } \\
\text { lymphadenopathy. }\end{array}$ & GP & Request outpatient ultrasound scan of neck. & $\begin{array}{l}\text { ACR White } \\
\text { Paper(16), } \\
\text { specialist } \\
\text { opinion }\end{array}$ \\
\hline \multirow[t]{2}{*}{ Adrenal opacities } & $<1 \mathrm{~cm}$ & $\mathrm{~N} / \mathrm{A}$ & No action required. & \multirow{2}{*}{$\begin{array}{l}\text { NLST (17), } \\
\text { ACR White } \\
\text { Paper (18) }\end{array}$} \\
\hline & $1-4 \mathrm{~cm}$ or Houndsfield Units $(\mathrm{HU})>10$ & Study team & $\begin{array}{l}\text { Annual scan within study. Inform participant and } \\
\text { GP. If stable on successive scans no further action. }\end{array}$ & \\
\hline
\end{tabular}




\begin{tabular}{|c|c|c|c|c|}
\hline & $>4 \mathrm{~cm}$ & Study team & Refer to local endocrine team. & \\
\hline \multirow[t]{3}{*}{$\begin{array}{l}\text { Abdominal aortic } \\
\text { dilatation }\end{array}$} & $<3 \mathrm{~cm}$ & $\mathrm{~N} / \mathrm{A}$ & No action required. & \multirow[t]{3}{*}{$\begin{array}{l}\text { NICE } \\
\text { guideline(19) }\end{array}$} \\
\hline & $\geq 3 \mathrm{~cm}<5 \mathrm{~cm}$ & GP & Refer to local vascular team for surveillance. & \\
\hline & 80 & Study team & $\begin{array}{l}\text { Urgent referral to local vascular team for } \\
\text { assessment. }\end{array}$ & \\
\hline $\begin{array}{l}\text { Abdominal solid } \\
\text { organ } \\
\text { abnormalities } \\
\text { (kidney, liver, } \\
\text { spleen) }\end{array}$ & $\begin{array}{l}\text { Case by case basis. Radiologists are encouraged only to } \\
\text { refer renal lesions if } \mathrm{HU}>10(20) \text { or if very likely to be } \\
\text { abnormal (21). }\end{array}$ & Study team & $\begin{array}{l}\text { Any abnormalities will be managed on a case by } \\
\text { case basis. }\end{array}$ & $\begin{array}{l}\text { NELSON (21), } \\
\text { ACR White } \\
\text { Paper (20) }\end{array}$ \\
\hline $\begin{array}{l}\text { Osteoporotic } \\
\text { (wedge) vertebral } \\
\text { fracture(s) }\end{array}$ & If reduction in height is $>50 \%$ normal & GP & Refer for bone density assessment. & $\begin{array}{l}\text { Specialist } \\
\text { opinion }\end{array}$ \\
\hline \multicolumn{5}{|c|}{$\begin{array}{l}\text { Additional notes } \\
\text { - Where the reporting radiologist has a high index of suspicion for cancer, but the study management protocol does not lead to an automatic urgent referral, } \\
\text { they have the ability to override the protocolised management plan and the study team will arrange the relevant urgent referral. } \\
\text { - As this is a lung cancer screening programme, every attempt is made to limit the images to the thoracic cavity in order to decrease detection of clinically } \\
\text { uncertain incidental findings, and to decrease radiation exposure to non-relevant areas } \\
\text { - Any emergency or very urgent findings will be managed by the study team on a case by case basis according to local services }\end{array}$} \\
\hline
\end{tabular}


1. Callister MEJE, Baldwin DR, Akram AR, Barnard S, Cane P, Draffan J, et al. British Thoracic Society Guidelines for the Investigation and Management of Pulmonary Nodules. Thorax. 2015 Aug;70(August):794-8.

2. Mets OM, De Jong PA, Chung K, Lammers J-WJ, Bram Van Ginneken \&, SchaeferProkop CM. Fleischner recommendations for the management of subsolid pulmonary nodules: high awareness but limited conformance - a survey study. Eur Radiol [Internet]. [cited 2019 Aug 22]; Available from: https://www.ncbi.nlm.nih.gov/pmc/articles/PMC5052295/pdf/330_2016_Articl e_4249.pdf

3. MacMahon H, Naidich DP, Goo JM, Lee KS, Leung ANC, Mayo JR, et al. Guidelines for Management of Incidental Pulmonary Nodules Detected on CT Images: From the Fleischner Society 2017. Radiology [Internet]. 2017;284(1):228-43. Available from: http://pubs.rsna.org/doi/10.1148/radiol.2017161659

4. Yip R, Henschke CI, Xu DM, Li K, Jirapatnakul A, Yankelevitz DF. Lung cancers manifesting as part-solid nodules in the national lung screening trial. Am J Roentgenol. 2017;208(5):1011-21.

5. De Hoop B, Van Ginneken B, Gietema H, Prokop M. Pulmonary perifissural nodules on CT scans: Rapid growth is not a predictor of malignancy. Radiology. 2012 Nov;265(2):611-6.

6. Silva M, Prokop M, Jacobs C, Capretti G, Sverzellati N, Ciompi F, et al. Long-Term Active Surveillance of Screening Detected Subsolid Nodules is a Safe Strategy to Reduce Overtreatment. J Thorac Oncol [Internet]. 2018 Oct 1 [cited 2019 Aug 12];13(10):1454-63. Available from: https://www.sciencedirect.com/science/article/abs/pii/S1556086418307640

7. Walter JE, Heuvelmans MA, de Jong PA, Vliegenthart R, van Ooijen PMA, Peters $\mathrm{RB}$, et al. Occurrence and lung cancer probability of new solid nodules at incidence screening with low-dose CT: analysis of data from the randomised, controlled NELSON trial. Lancet Oncol [Internet]. 2016;2045(16):1-10. Available from: http://dx.doi.org/10.1016/S1470-2045(16)30069-9

8. Rudolf M, Reilly JO, Parnham J, Sloan N, Crowe E, O’Mahony R, et al. Chronic obstructive pulmonary disease in over 16s: diagnosis and management | Guidance and guidelines | NICE. 2016; Available from: https://www.nice.org.uk/guidance/cg101\%0Ahttps://www.nice.org.uk/guidanc e/CG101/chapter/1-Guidance\#managing-stablecopd\%0Ahttps://www.nice.org.uk/guidance/cg101/chapter/Appendix-A-TheGuideline-Development-Group

9. Roberts HR, Wells AU, Rubens MB, Cole PJ, Hansell DM, Milne DG, et al. Airflow obstruction in bronchiectasis: Correlation between computed tomography features and pulmonary function tests. Thorax. 2000;55(3):198-204.

10. Kliment CR, Araki T, Doyle TJ, Gao W, Dupuis J, Latourelle JC, et al. A comparison of visual and quantitative methods to identify interstitial lung abnormalities. BMC Pulm Med. 2015 Oct 29;15(1).

11. Flaherty KR, Brown KK, Wells AU, Clerisme-Beaty E, Collard HR, Cottin V, et al. Design of the PF-ILD trial: A double-blind, randomised, placebo-controlled phase III trial of nintedanib in patients with progressive fibrosing interstitial lung disease. BMJ Open Respir Res. 2017;4(1):1-7.

12. Bhatnagar R, Maskell N. The modern diagnosis and management of pleural effusions [Internet]. Vol. 351, BMJ (Online). 2015 [cited 2018 Sep 4]. Available from: http://www.bmj.com/subscribe

13. SIGN: Scottish Intercollegiate Guidelines Network. Guideline 59: Community Management of Lower Respiratory Tract Infection in Adults. SIGN: Scottish 
Intercollegiate Guidelines Network. 2002.

14. Munden RF, Carter BW, Chiles C, MacMahon H, Black WC, Ko JP, et al. Managing Incidental Findings on Thoracic CT: Mediastinal and Cardiovascular Findings. A White Paper of the ACR Incidental Findings Committee. J Am Coll Radiol [Internet]. 2018;1-10. Available from: https://doi.org/10.1016/j.jacr.2018.04.029

15. McComb BL, Munden RF, Duan F, Jain AA, Tuite C, Chiles C. Normative reference values of thoracic aortic diameter in American College of Radiology Imaging Network (ACRIN 6654) arm of National Lung Screening Trial. Clin Imaging. 2016;40(5):936-43.

16. Hoang JK, Langer JE, Middleton WD, Wu CC, Hammers LW, Cronan JJ, et al. Managing Incidental Thyroid Nodules Detected on Imaging: White Paper of the ACR Incidental Thyroid Findings Committee. J Am Coll Radiol [Internet]. 2015 Feb [cited 2019 Aug 28];12(2):143-50. Available from:

http://www.ncbi.nlm.nih.gov/pubmed/25456025

17. Klysik M. Incidental Non-Cardiovascular, Non-Pulmonary Findings Identified in a Low-Dose CT Lung Cancer Screening Population: Prevalence and Clinical Implications. Int J Radiol Imaging Technol. 2015;1(1).

18. Berland LL, Silverman SG, Gore RM, Mayo-Smith WW, Megibow AJ, Yee J, et al. Managing incidental findings on abdominal CT: White paper of the ACR incidental findings committee. J Am Coll Radiol [Internet]. 2010;7(10):754-73. Available from: http://dx.doi.org/10.1016/j.jacr.2010.06.013

19. National Institute for Health and Care Excellence. Guideline scope Abdominal aortic aneurysm: diagnosis and management [Internet]. 2018. Available from: https://www.nice.org.uk/guidance/gid-cgwave0769/documents/final-scope

20. Herts BR, Silverman SG, Hindman NM, Uzzo RG, Hartman RP, Israel GM, et al. Management of the Incidental Renal Mass on CT: A White Paper of the ACR Incidental Findings Committee. J Am Coll Radiol [Internet]. 2018;15(2):264-73. Available from: https://doi.org/10.1016/j.jacr.2017.04.028

21. van de Wiel JCM, Wang Y, Xu DM, van der Zaag-Loonen HJ, van der Jagt EJ, van Klaveren RJ, et al. Neglectable benefit of searching for incidental findings in the Dutch-Belgian lung cancer screening trial (NELSON) using low-dose multidetector CT. Eur Radiol. 2007;17(6):1474-82. 